\title{
Acetylation of wood in combination with polysiloxanes to improve water-related and mechanical properties of wood
}

\author{
Malte Pries • Roland Wagner $\cdot$ Karl-Heinz Kaesler • \\ Holger Militz $\cdot$ Carsten Mai
}

Received: 25 May 2012/Published online: 2 March 2013

(C) The Author(s) 2013. This article is published with open access at Springerlink.com

\begin{abstract}
Scots pine sapwood was acetylated with ethyltriacetoxysilane using acetic acid as a solvent and sulfuric acid as a catalyst. A weight percent gain (WPG) of $14 \%$ and cell wall bulking of $7 \%$ were obtained after $5 \mathrm{~h}$ of reaction time. Pine specimens were acetylated with acetic anhydride in the presence of $1 \%$ ethyltriacetoxysilane, dihydroxy-functional siloxane, acetoxy-functional siloxane, aminofunctional siloxane and non-functional siloxane, respectively. Acetoxy-functional siloxane induced the greatest reduction in water uptake with a water repellent effectiveness after $24 \mathrm{~h}$ of up to $62 \%$ as compared to acetylated wood. WPG and cell wall bulking increased compared to solely acetylated wood with increasing concentrations of acetoxy-functional siloxane in acetic anhydride; anti-shrink efficiency, however, did not increase. Fungal resistance of pine sapwood and beech as well as mechanical strength properties did not change when $20 \%$ acetoxy-functional siloxane was added to acetic anhydride compared to solely acetylated specimens.
\end{abstract}

\section{Introduction}

Chemical modification has the potential to greatly improve properties of wood (Rowell 1983). The most studied process is by far the acetylation of wood which has undergone market introduction. Acetylation reportedly improved fungal resistance, photo-stability, dimensional stability and weathering performance of wood (Brelid et al. 2000; Chang and Chang 2001; Hill et al. 2005; Rowell 1983). The most

\footnotetext{
M. Pries $\cdot$ H. Militz $\cdot$ C. Mai $(\varangle)$

Wood Biology and Wood Products, Burckhardt Institute, Georg-August-University Göttingen, Büsgenweg 4, 37077 Göttingen, Germany

e-mail: cmai@gwdg.de

R. Wagner · K.-H. Kaesler

Momentive Performance Materials, Technology, Buildg. R20, 51368 Leverkusen, Germany
} 
abundant reaction sites in wood, the hydroxyl groups, are acetylated in the process by use of acetic anhydride (AA) under release of acetic acid. Because of the greater volume of acetyl groups compared to hydroxyl groups, cell wall bulking is observed (Stamm 1964). Reduction in capillary water uptake, however, occurs only to a minor extent.

Silicones have experienced a widespread use in many industrial applications. They are widely used in the construction sector to improve water repellence of masonry (Mayer 1998) or to improve properties of textiles (Kim 2001). Silicones have been tested on wood to enhance water repellence and showed great effectiveness in reducing water uptake (Hager 1995; Lukowsky et al. 1997). Hager (1995) used silicone micro-emulsions to treat wood and found a reduction in capillary water uptake by $80 \%$ as compared to the control after $24 \mathrm{~h}$ at $1 \%$ silicone content in the emulsion. Lukowsky et al. (1997) tested the effectiveness of similar micro-emulsions and some additional silicone formulations and found water repellent effectiveness in a submersion test of up to $50 \%$ after $24 \mathrm{~h}$. Ghosh (2009) found high water repellence when wood was treated with a water solvent-based solution of amino-functional silicones. A water repellent effectiveness of approximately $50 \%$ was reached after $24 \mathrm{~h}$ of water submersion with an amino-functional silicone comprised of 30 dimethyl siloxane units.

Silicones can therefore be used to hydrophobize wood; however, they are not easy to solubilize in water because of their strong water repellence. Real solutions can only be made by using high proportions of organic solvents in the solution which restricts the application in conventional impregnation plants. If emulsions are used, costs of emulsifiers have to be considered. In addition, the emulsifier will stay in the wood after impregnation and offset hydrophobation of the material by silicone. The micro-emulsions used by Hager (1995) and Lukowsky et al. (1997) solved this problem by using silanes and functionalized polysiloxanes as emulsifier or co-emulsifier, respectively. These emulsions, however, are not stable and a short solution stability of only approximately $24 \mathrm{~h}$ is obtained. This makes the use of these formulations not viable in impregnation plants (Lukowsky et al. 1997). Another possibility is the impregnation of solid wood with silicone using supercritical $\mathrm{CO}_{2}$ as solvent (Eastman et al. 2009).

The acetylation procedure with acetic anhydride offers the opportunity to solve silicones directly in the acetylation reagent to impregnate wood without further treatment steps. Acetoxysilanes can acetylate hydroxyl groups via transesterification and releasing silanol compounds as leaving group; release of acetic acid from the silane is therefore omitted.

\section{Materials and methods}

\section{Organo-silicon compounds}

Ethyltriacetoxysilane (TAS) was used as silicon-based acetylation chemical. A short-chained silicone (Si 200 TP 3031), containing 70-100 \% of $\alpha$ - $\omega$-functional polydimethylsiloxanediol with a mean of 6 dimethylsiloxane units (D6) and 0-30\% 
of octamethylcyclotetrasiloxane was used as a siloxane backbone, which can easily be combined with ethyltriacetoxysilane. The silicone oils M5 and M100 are nonfunctional polydimethylsiloxanes (PDMS). M5 has a mean chain length of D6-7 and M100 of D80. Amino D9 and Amino D28 are $\alpha-\omega$-functional diaminopolydimethylsiloxanes with a chain length of D9 and D28. All organo-silicon-compounds were supplied by Momentive Performance Materials GmbH (Leverkusen, Germany).

\section{Wood samples}

Pine sapwood (Pinus sylvestris L.) blocks (defined as ASE specimens) measuring $20 \times 20 \times 10 \mathrm{~mm}^{3}(r \times t \times l)$ were used to determine weight percent gain (WPG), cell wall bulking, anti-shrink efficiency (ASE) and water uptake. Blocks of beech wood (Fagus sylvatica L.) and pine sapwood (P. sylvestris L.) according to EN 113 (1996) were used for basidiomycete testing. Pine sapwood (P. sylvestris L.) stakes measuring $10 \times 10 \times 180 \mathrm{~mm}^{3}(r \times t \times l)$ were used to determine bending strength and those measuring $10 \times 10 \times 150 \mathrm{~mm}^{3}(r \times t \times l)$ to determine impact bending strength. Pine sapwood had an average density of $0.51 \mathrm{~g} \mathrm{~cm}^{-3}$, while the beech wood showed a density of $0.68 \mathrm{~g} \mathrm{~cm}^{-3}$.

Acetylation of wood with ethyltriacetoxysilane

Acetylation with ethyltriacetoxysilane (TAS) was carried out with pure TAS and in a mixture with acetic acid serving as a solvent and swelling agent for wood (Mantanis et al. 1994). The mixture consisted of $30 \%$ TAS mixed with $70 \%$ acetic acid statically dried over molecular sieves (4 ̊).

Acetylation was performed with and without catalyst. The reaction of pure TAS was catalyzed with $0.25 \% \mathrm{H}_{2} \mathrm{SO}_{4}$ (w/w of TAS), while the following catalysts were used in the mixture of $30 \%$ TAS with $70 \%$ acetic acid: $\mathrm{MgCl}_{2}(0.8 \% \mathrm{w} / \mathrm{w})$, potassium acetate $(\mathrm{KAc})$, triethylamine $(1 \% \mathrm{w} / \mathrm{w})$ and $\mathrm{H}_{2} \mathrm{SO}_{4}(0.07 \% \mathrm{w} / \mathrm{w})$. To apply KAc, the wood specimens were vacuum impregnated with $10 \%(\mathrm{w} / \mathrm{w})$ aqueous solution according to EN 113 and dried prior to the acetylation process at $103{ }^{\circ} \mathrm{C}$ (Obataya and Minato 2008). The other catalysts were directly mixed into the treatment solution.

After impregnation with the acetylation reagent (according to EN 113), the specimens were heated in the solution to $120{ }^{\circ} \mathrm{C}$ for $5 \mathrm{~h}$, while protected against moisture by a $\mathrm{CaCl}_{2}$ tube. After the reaction, the specimens were extracted in a soxhlet extractor with acetic acid for $6 \mathrm{~h}$ under exclusion of moisture by $\mathrm{CaCl}_{2}$ and subsequently with ethanol for $6 \mathrm{~h}$ to remove acetic acid. The acetylation reaction was assessed by measuring WPG, cell wall bulking and recording IR spectra.

Preparation of an acetoxy-functional polydimethylsiloxane

TAS was brought into a round-bottomed flask equipped with a reflux condenser and a dropping funnel, and Si 200 was added drop-wise until a ratio of $2 \mathrm{~mol}$ of TAS to $1 \mathrm{~mol} \mathrm{Si} 200$ was reached. During the addition, the temperature rose from 
approximately $20-38{ }^{\circ} \mathrm{C}$. After the addition, the product was confirmed by ${ }^{1} \mathrm{H}$ NMR spectroscopy in $\mathrm{CDCl}_{3}$ on a $400 \mathrm{MHz}$ spectrometer Bruker Avance 400 (Bruker, Bremen, Germany). A NMR diffusion experiment (DOSY) was applied to distinguish between ethyl groups $(0.96-1.14 \mathrm{ppm})$ attached to a silane [diffusion coefficient from $10^{-8.83} \mathrm{~m}^{2} \mathrm{~s}^{-1}$ (monomer) to $10^{-8.96} \mathrm{~m}^{2} \mathrm{~s}^{-1}$ (dimer and trimer)] and attached to a polysiloxane backbone (diffusion coefficient from $10^{-9.09}$ to $10^{-9.17} \mathrm{~m}^{2} \mathrm{~s}^{-1}$ ). After the reaction, no acetyl groups were left which were only attached to a silane. The structure of the product is depicted in Fig. 1.

Acetylation of wood in the presence of organo-silicon compounds

Impregnation of all wood specimens was done according to EN 113 (1996). The specimens were left in the solution and heated to $120{ }^{\circ} \mathrm{C}$ for $5 \mathrm{~h}$. After the reaction, the samples were dropped into deionized water to quench the reaction. They were left in water for 2 days with a water change after 1 day. Subsequently, the specimens were dried at room temperature for 2 days and finally dried at $103{ }^{\circ} \mathrm{C}$ for $24 \mathrm{~h}$. Eight ASE specimens at a time were treated with a solution of acetic anhydride (AA) and the following organo-silicon compounds:

1. $1 \%$ acetoxy-functional silane (1st educt of No. 3 ).

2. $1 \%$ Si 200 (2nd educt of No. 3).

3. $1 \%$ acetoxy-functional siloxane (product of No. 1 and 2).

4. $1 \% \mathrm{M} 5$.

5. $1 \% \mathrm{M} 100$.

6. $1 \%$ Amino D9.

7. $1 \%$ Amino D28.

In another approach, the acetoxy-functional siloxane (No. 3) was mixed with AA in various ratios $(1,3,6,10$ and $20 \%)$. These solutions were used to impregnate 16 ASE specimens at a time and to determine WPG, cell wall bulking, water uptake and acetyl content.WPG and cell wall bulking were calculated according to Xiao et al. (2010).

\section{Infrared spectroscopy}

Fourier-transform infrared (FT-IR) spectra were recorded of the cross-sections of the specimens by means of the attenuated total reflection (ATR) technique (DuraSamplIRII, SensIR Technologies, Warrington, UK), using a Vektor 22 spectrophotometer (Bruker, Bremen, Germany) (32 scans, $4 \mathrm{~cm}^{-1}$ resolution). Background spectra were collected with the empty ATR unit. Three spectra of each
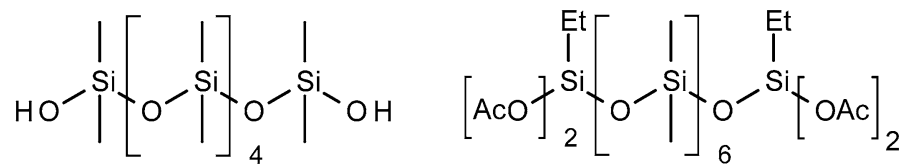

Fig. 1 Mean structure of Si200 (left) and idealized product (right) 
specimen were normalized to an absorption of 2 absorption units at $1,505 \mathrm{~cm}^{-1}$ (aromatic stretch vibration of lignin), baseline corrected using the rubber band method in the OPUS software (64 points, Bruker, Bremen, Germany) and subsequently averaged.

\section{Water uptake test}

Eight ASE specimens per treatment were submerged in approximately $300 \mathrm{ml}$ water and weighted after 2, 4, 6 and $24 \mathrm{~h}$ of submersion. Water uptake and water repellent effectiveness (WRE) were calculated according to Donath et al. (2006).

\section{Determination of the acetyl content}

Eight ASE specimens were milled in a centrifugal mill (Retsch ZM100, Retsch, Germany) using a $0.5 \mathrm{~mm}$ sieve; the milled material was soaked in water and dried subsequently at $103{ }^{\circ} \mathrm{C}$ to remove acetic acid. Approximately $0.5 \mathrm{~g}$ of each material was weighted into a flat-bottomed flask and $10 \mathrm{ml}$ of $75 \%(\mathrm{v} / \mathrm{v})$ ethanol-water mixture was added. This mixture was heated under agitation to $50{ }^{\circ} \mathrm{C}$ for $30 \mathrm{~min}$. $\mathrm{NaOH}\left(25 \mathrm{ml}, 0.5 \mathrm{~mol} \mathrm{l}^{-1}\right)$ was added and the flasks were kept at $50{ }^{\circ} \mathrm{C}$ for $30 \mathrm{~min}$. To neutralize the mixture $25 \mathrm{ml} \mathrm{H}_{2} \mathrm{SO}_{4}\left(0.25 \mathrm{~mol} \mathrm{l}^{-1}\right)$ was added, the mixture was filtered and diluted with water to $250 \mathrm{ml}$.

The acetic acid content was determined with an HPLC equipped with an RIdetector (Waters 1525 pump, Waters $717^{\text {plus }}$ auto sampler, Waters 2414 RI-detector, Waters Corporation, Milford, MA, USA) using $0.005 \mathrm{M} \mathrm{H}_{2} \mathrm{SO}_{4}$ as solvent. The acetyl content was related to the weight of the specimen tested.

\section{Fungal decay test}

Resistance to basidiomycetes was assessed according to EN 113 (1996). Twenty pine sapwood specimens and 20 beech wood samples were impregnated either with acetic anhydride or with a mixture of acetoxy-functional siloxane $(20 \% \mathrm{w} / \mathrm{w})$ in acetic anhydride as described above. Afterward the specimens were heated in the solution to $120{ }^{\circ} \mathrm{C}$. Ten specimens of each kind were heated for $1 \mathrm{~h}$ and the other ten for $2 \mathrm{~h}$. After the reaction time, the specimens were submersed into cold water and kept submerged to perform leaching according to EN 84 (1997).

After careful oven-drying $\left(103{ }^{\circ} \mathrm{C}\right)$, weighing and conditioning $\left(20{ }^{\circ} \mathrm{C}, 65 \%\right.$ $\mathrm{RH}$ ), the specimens were incubated in kolle flasks with Coniophora puteana (BAM Ebw. 15) (pine sapwood) and Trametes versicolor (CTB 863 A) (beech wood) for 16 weeks. Two treated and two untreated control specimens, respectively, were incubated in one kolle flask according to CEN/TS 15083-1 (2004). After incubation, the mass loss was determined.

Bending and impact bending test

Bending strength and modulus of elasticity were assessed according to DIN 52186 (1978) with 9 replicates per treatment (Zwick/Z010, Zwick, Ulm Germany) and 
impact bending strength according to DIN 52189 (1981) with 12 replicates per treatment (Resil Impactor, Ceast, Turin, Italy). The specimens were acetylated with pure acetic anhydride (AA) and with mixtures of 1,5 and $10 \%$ acetoxy-functional polysiloxane and AA for $6 \mathrm{~h}$ in the same way as described above. The reaction was quenched with water, and the WPG of the dry specimens was determined after 2 days of water leaching. Prior to testing, the specimens were conditioned at $20{ }^{\circ} \mathrm{C}$ and $65 \% \mathrm{RH}$, and the equilibrium moisture content (EMC) was determined.

\section{Results and discussion}

Acetylation with ethyltriacetoxysilane (TAS)

Ethyltriacetoxysilane (TAS) can acetylate hydroxyl groups of wood via a transesterification reaction (Fig. 2). The resulting silanol groups produced from TAS can form siloxane groups upon dehydration and further generate a threedimensional silicon dioxide network within the wood structure. In contrast to acetylation with acetic anhydride, this reaction principally does not release any acetic acid and the generated polysiloxane might further enhance the properties of the products.

The reaction of pure ethyltriacetoxysilane (TAS) with wood resulted only in negligible WPG and cell wall bulking. Soaking of ASE specimens in pure TAS revealed slight shrinkage $(0.04 \%$ of the cross-sectional area) after impregnation rather than swelling. This indicates that TAS does not penetrate into the cell wall and is therefore not able to react with the cell wall matrix. The minor shrinkage was probably due to complete dehydration of the specimens by the silane, which reacts with water upon formation of silanol groups and acetic acid.

The addition of $\mathrm{H}_{2} \mathrm{SO}_{4}$ as a catalyst in TAS resulted in mean bulking of $1.3 \%$ and WPG of $7.8 \%$. It therefore seems possible to acetylate wood without a solvent by using pure TAS, but effective acetylation in a reasonable time is not achievable. Swelling of the cell wall is indispensable (Rowell 1983) to acetylate wood more successfully with TAS. A $30 \%$ solution of TAS in acetic acid caused swelling of the wood to an extent comparable to water and allowed the silane to enter the cell wall. In absence of a catalyst, no reaction of TAS with wood took place. Triethylamine and $\mathrm{H}_{2} \mathrm{SO}_{4}$ induced noteworthy WPG and bulking, while magnesium
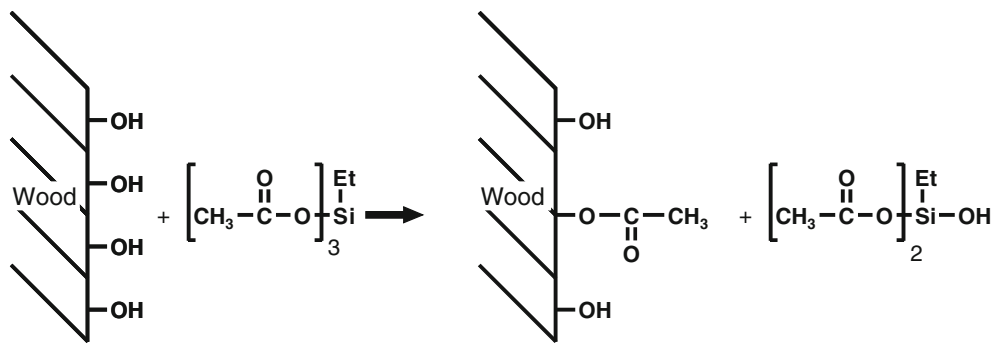

Fig. 2 Reaction of wood with ethyltriacetoxysilane 
chloride and potassium acetate did not. Using triethylamine, the treatment resulted in a WPG of $3.3 \%$ and a bulking of $2.7 \%$; acetylation in the presence of $\mathrm{H}_{2} \mathrm{SO}_{4}$ led to a WPG of $14 \%$ and a bulking of $7 \%$ after $5 \mathrm{~h}$ of reaction time.

Infrared spectra revealed successful acetylation (Fig. 3). Absorption at $1,740 \mathrm{~cm}^{-1}$ ( $\mathrm{C}=\mathrm{O}$ stretching), $1,370 \mathrm{~cm}^{-1}$ (methyl vibration), $1,220 \mathrm{~cm}^{-1}$ (C-O stretching) and $897 \mathrm{~cm}^{-1}$ (methyl vibration) were strongly increased in the specimens acetylated with a mixture of TAS, acetic acid and $\mathrm{H}_{2} \mathrm{SO}_{4}$ as compared to the control. The peak at approximately $1,000 \mathrm{~cm}^{-1}$ (assigned to $\mathrm{C}-\mathrm{O}$ stretch vibration in polysaccharides) probably increased due to the presence of siliconoxygen bonds, which were formed despite of the extraction after treatment. Acetylation catalyzed with triethylamine resulted in much smaller WPG and cell wall bulking. A slightly increased absorption appeared at 1,740 and $1,220 \mathrm{~cm}^{-1}$ assigned to acetyl groups. Other absorption peaks did not differ from those of the control.

Bulking, WPG and water uptake after modification with various combinations of polysiloxane and acetic anhydride

The two non-functional polydimethylsiloxanes (PDMS) (M5 and M100), especially M100, did not dissolve well in AA. The amino-functional siloxanes easily dissolved only in warm AA, while the other three materials, TAS, Si200 and acetoxyfunctional siloxane, easily dissolved in cold AA. WPG and bulking of all treated specimens were very similar and did not differ from the solely acetylated specimens (Fig. 4).

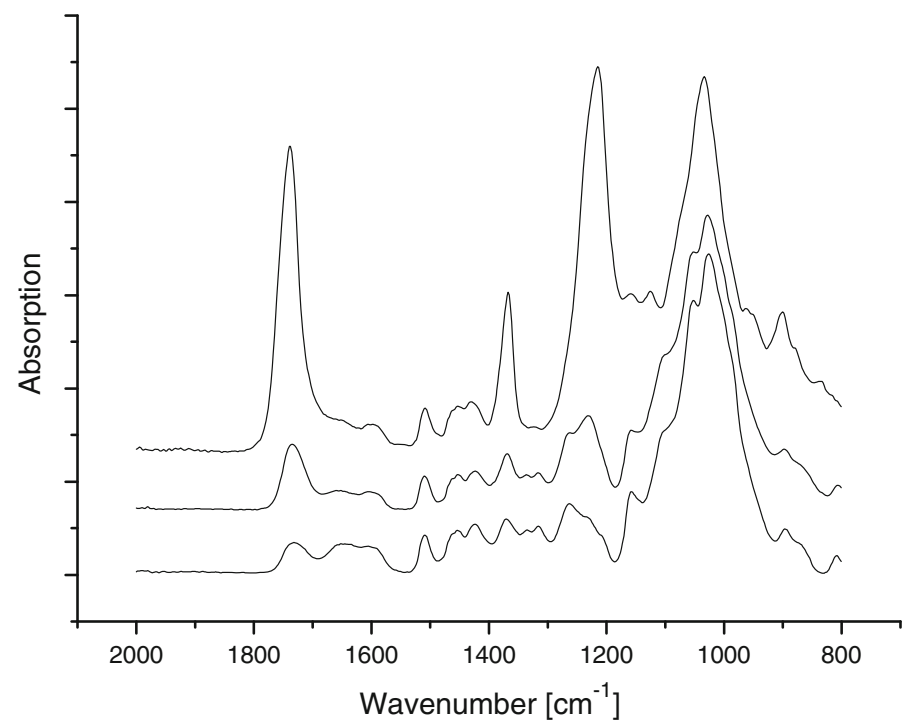

Fig. 3 FTIR spectra of control (bottom), triethylamine catalyzed acetylation (middle) and $\mathrm{H}_{2} \mathrm{SO}_{4}$ catalyzed acetylation (top) 


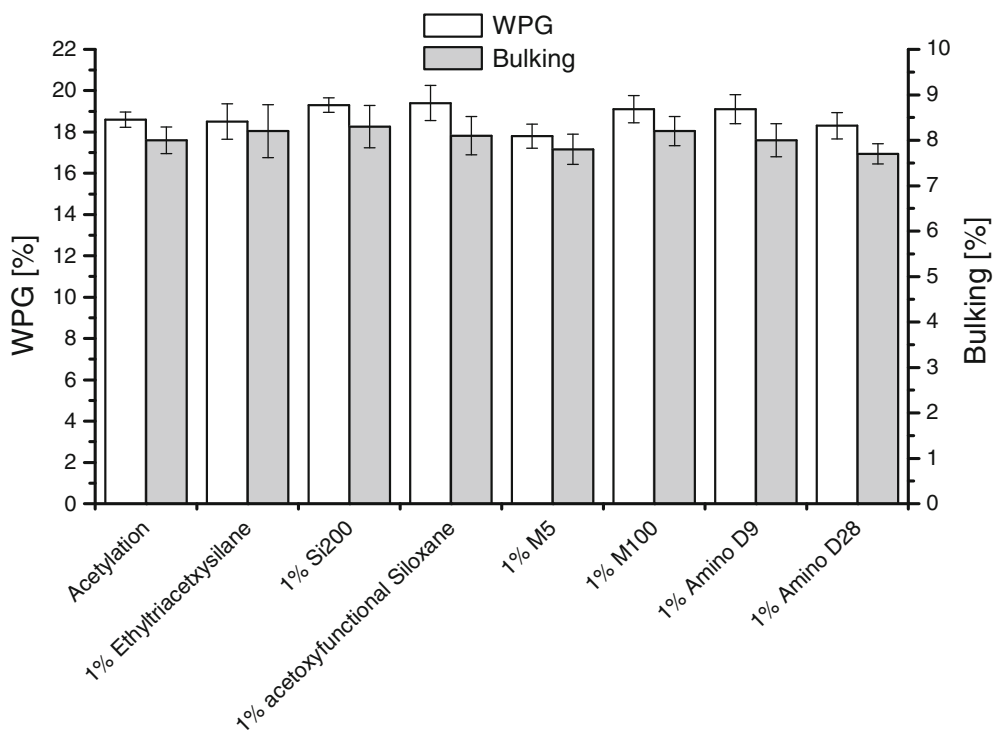

Fig. 4 WPG and bulking values of wood treated with various siloxanes in combination with acetic anhydride, mean values and standard deviations

The non-functionalized siloxane (M5 and M100) as well as the amino-functional siloxane (D9 and D28) reduced water uptake only to a minor extent compared to the acetylated control. The acetoxy-functional siloxane, however, clearly reduced the water uptake to a greater extent than all other materials (Fig. 5a) with a WRE of $33 \%$ related to acetylated wood. In subsequent water submersion tests, the two educts TAS, Si200 and their product, the acetoxy-functional siloxane, exhibited major changes. In the second test, TAS and acetoxy-functional siloxane did not differ, but in the third (not shown) and fourth tests the acetoxy-functional siloxane again reduced the water uptake more than both of its educts (Fig. 5b) with a WRE of $49 \%$ as compared to the acetylated controls.

In general, water uptake of wood can be reduced through (a) blocking of penetration pathways for capillary water uptake and (b) altering of the surface properties of the wood in a way that hinders water uptake. The gradual decrease in water uptake from the first to the fourth experiment observed with the specimens treated with acetoxy-functional PDMS, TAS and Si200 suggests an alteration of the wood surface rather than pathway blocking. The reason for the reduction in water uptake in subsequent tests may be the increasing orientation of the siloxane chain due to several steps of wetting and high-temperature drying. Kim (2001) also found a strong increase in hydrophobation of textile materials after treatment with aminofunctional siloxanes when the drying temperature was raised. The heat treatment is expected to increase the orientation of the siloxane in a way that the hydrophilic parts of the chain are facing toward the wood cell wall and the hydrophobic parts orient toward the lumens. This process is called activation (Kim 2001). In nonfunctional siloxane, the $\mathrm{Si}-\mathrm{O}-$ backbone will mostly face toward the wood matrix 

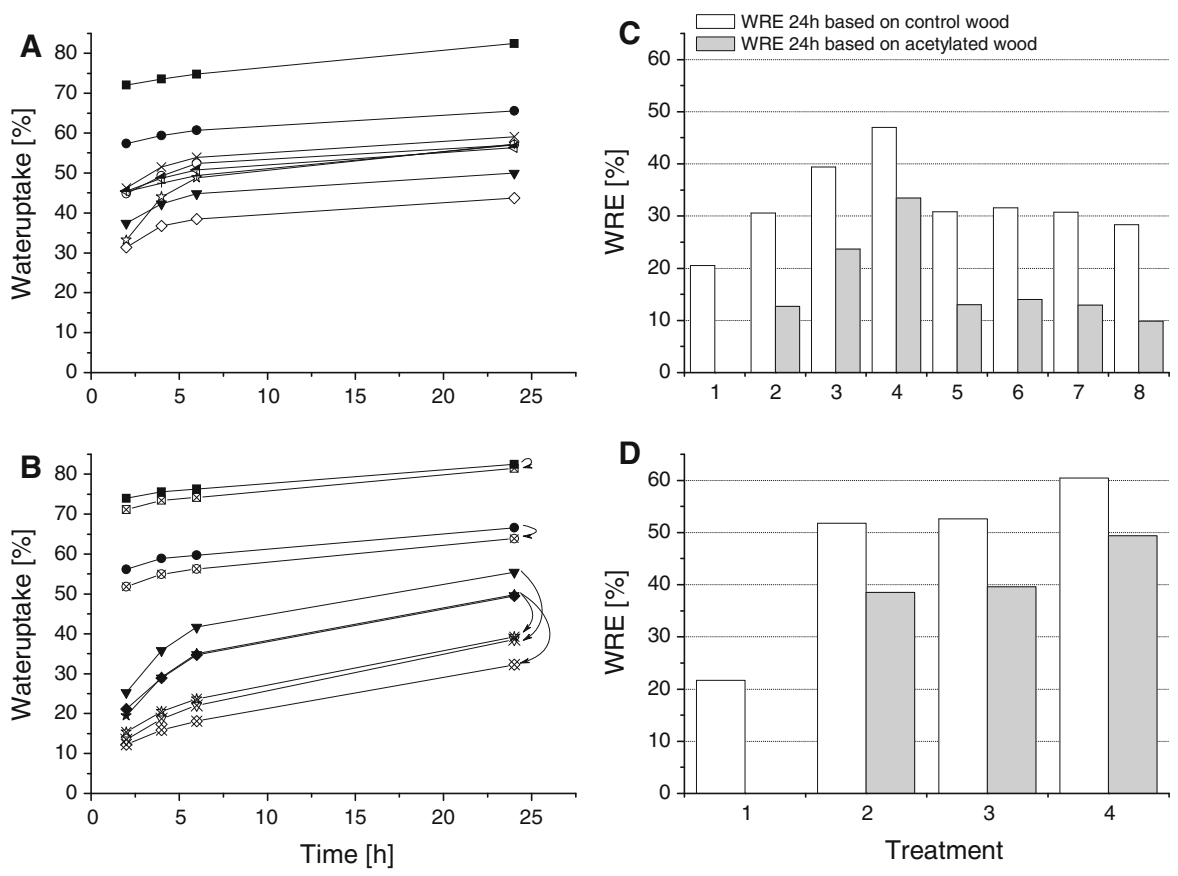

- Control; - Acetylation (1); - Acetylation + 1\% Ethyltriacetxysilane (2);

$\checkmark$ Acetylation $+1 \%$ acetoxyfunctional Siloxane (4); - - Acetylation $+1 \%$ M5 (5)

Acetylation + 1\% Si200 (3)

Acetylation $+1 \%$ Amino D9 (7); $\quad \times$ Acetylation + 1\% Amino D28 (8)

Fig. 5 Water uptake of various siloxane-treated specimens. a First submersion test, $\mathbf{b}$ second and fourth submersion of control and specimens with treatment no. 1, 2, 3, 4, c WRE in first submersion test, $\mathbf{d}$ WRE in fourth submersion test

while the hydrophobic methyl groups are directed outwards (Kim 2001; Noll 1968). In contrast to previous studies (Ghosh 2009), the amino-functional siloxane did not cause strong hydrophobation. The previously found strong reduction in water uptake by amino-functional siloxane (which is a relatively hydrophilic material) was suggested to be due to pathway blocking which prevented capillary penetration of water (Ghosh 2009; Weigenand et al. 2007). In this study, the interaction of amino groups with the wood surface (as described for textiles by Bereck et al. 2001) might be weakened because of the introduction of acetyl groups. These might interfere with the interactions which are normally formed with hydroxyl groups. In addition, acetylation of amino groups can occur in the presence of acetic anhydride (Naik et al. 2004). The following studies focused on acetoxy-functional siloxane, because best results were obtained with this material.

WPG, bulking and acetyl content after modification with combinations of acetoxy-functional siloxane and acetic anhydride

The WPG increased linearly with increasing content of the acetoxy-functional siloxane in AA (Fig. 6). Cell wall bulking increased slightly but significantly with 
increasing siloxane content in AA (Fig. 6). Analysis of variance gave a $p$ value of $<0.0001$ indicating high significance. Bulking was significantly different from the control when 6, 10 and $20 \%$ siloxane were added to AA.

Bulking of acetylated wood is caused by acetyl groups introduced into the cell wall (Rowell 1983). Therefore, the acetyl content should increase with increasing bulking. Determination of the acetyl content, however, revealed that higher bulking was not attributable to a higher degree of acetylation in case of higher PDMS content in the mixture (Fig. 7). Obviously, the siloxane was able to penetrate the wood cell wall to a certain extent and to increase bulking. Ghosh (2009) treated wood with water solvent-based solutions of siloxanes with similar chain length as used here and found considerable bulking. This suggests that siloxanes are able to penetrate the cell wall despite their high molecular mass. While the ASE of the acetylated specimens was $48.4 \%$, that of the $20 \%$ mixture amounted to $48.7 \%$ and hence did not significantly increase. The reason for this unchanged ASE was a slight increase in maximum swelling in water as compared to the untreated control and the solely acetylated specimens which offset the greater bulking.

\section{Water uptake}

The water uptake test revealed a strong hydrophobation of the wood treated with acetoxy-functional siloxane. The first submersion test still indicated differences between $1 \%$ on the one hand and 3, 6, 10 and $20 \%$ on the other hand (Fig. 8a, c). The specimens were soaked in water and dried two times at $103{ }^{\circ} \mathrm{C}$ prior to a second submersion. In this second test, the differences between the treatments nearly disappeared (Fig. 8b); the WRE ranged from $62 \%$ (1\% siloxane) to $71 \%$ (6\% siloxane) without showing a clear trend (Fig. 8d). Addition of $1 \%$ acetoxy-

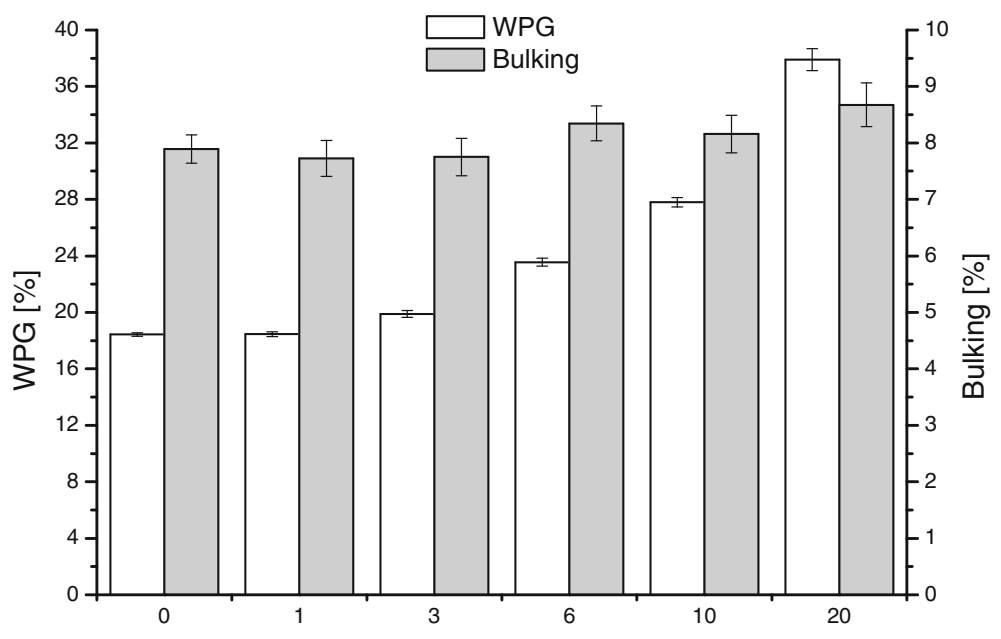

Proportion of acetoxyfunctional Siloxane to acetic anhydride [\%]

Fig. 6 WPG and bulking induced through treatment with different acetic anhydride/siloxane mixtures, mean values and standard deviations 


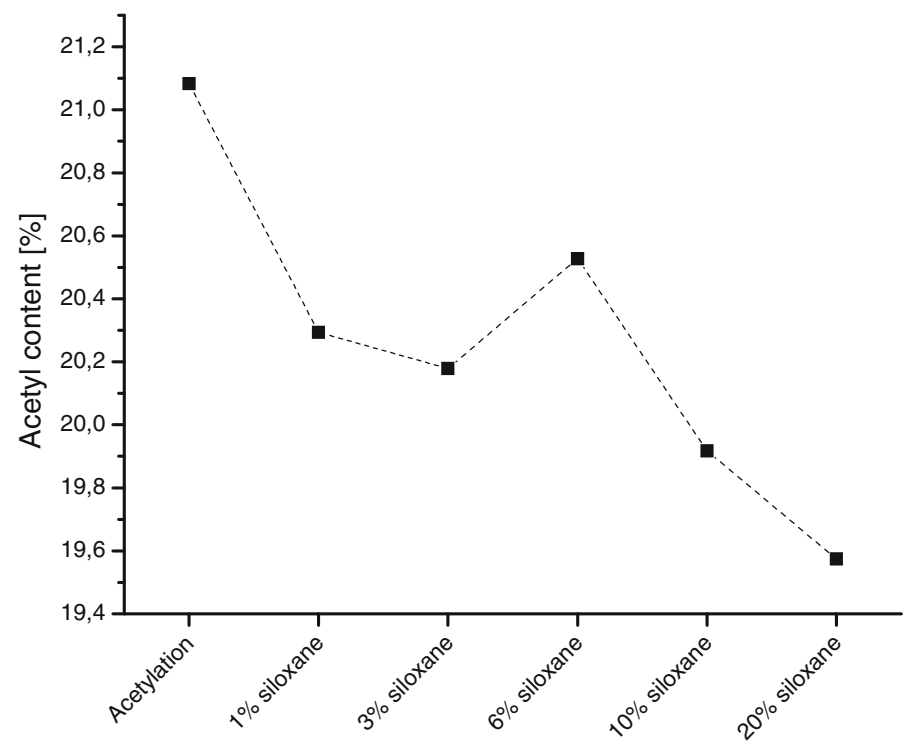

Fig. 7 Acetyl content of various acetanhydride-siloxane mixtures

functional siloxane therefore appeared to be sufficient to decrease the water uptake to a maximum extent. This result indicates that pathway blocking is not the major reason for increased hydrophobation, because it can hardly explain increasing hydrophobation in subsequent water uptake tests. Furthermore, an increased concentration of the siloxane should lead to increased pathway blocking and thus enhance hydrophobation but this was not the case. It is therefore assumed that water uptake is reduced due to alteration of the (inner) wood surface; addition of $1 \%$ siloxane seems to be sufficient for covering the inner surface of the wood. For maximum reduction in water uptake at $1 \%$ siloxane concentration, however, a more intense activation process is needed, which encompasses extended heating to enhance the orientation of the siloxane chains.

\section{Fungal decay}

In order to study the influence of the acetoxy-functional siloxane, a low degree of acetylation was established which still allowed fungal decay. The WPG of the specimens increased by addition of acetoxy-functional siloxane to AA, but the mass loss after fungal incubation was nearly the same (Table 1). A $t$ test performed, respectively, on the pairs "acetylation $(x \mathrm{~h})$ and acetylation $+20 \%$ siloxane $(x \mathrm{~h})$ " only revealed a different result between acetylation for $2 \mathrm{~h}$ in beech wood and acetylation with $20 \%$ siloxane in beech wood for $2 \mathrm{~h}$ (Table 1). Thus, the resistance to fungal decay is exclusively attributable to the acetyl content and not to the presence of siloxane chains. The significantly higher mass loss in the case of beech $(2 \mathrm{~h}$ acetylation) can be explained by a lower acetyl content which resulted 

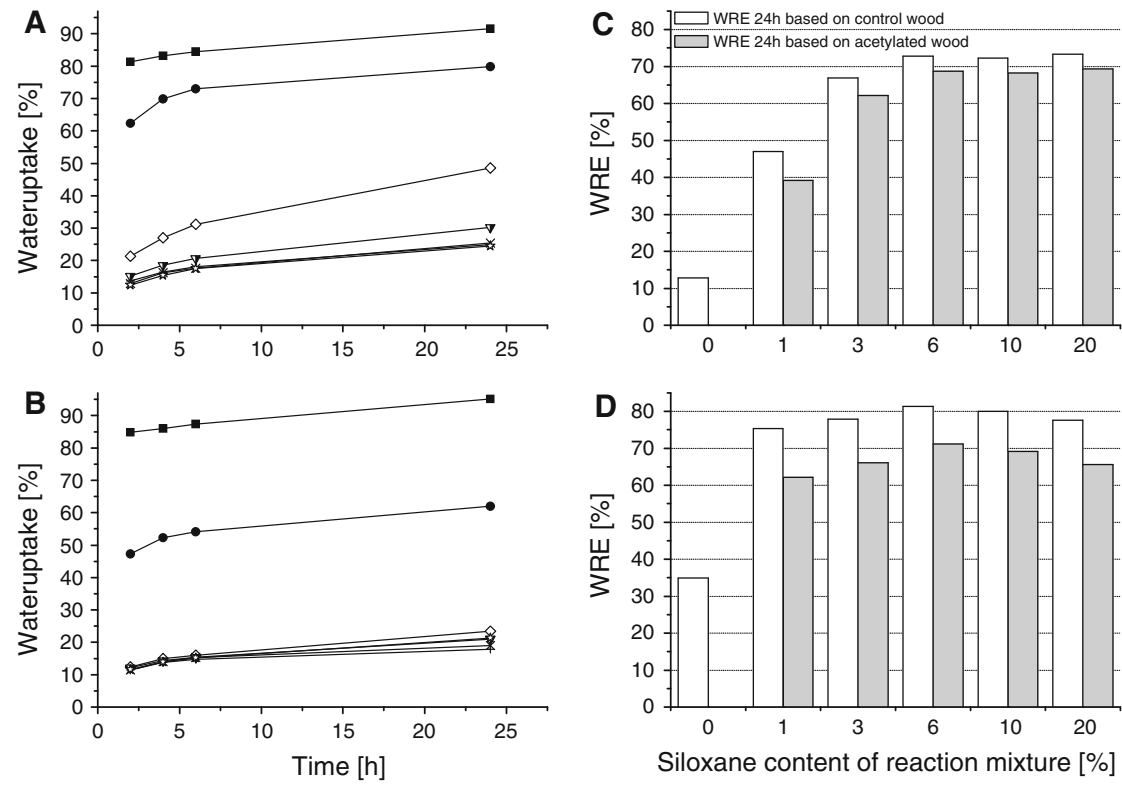

Siloxane content of reaction mixture [\%]

- Control; - - Acetylation; $\checkmark$ Acetylation $+1 \%$ acetoxyfunctional siloxane; $-\nabla-$ Acetylation $+3 \%$ acetoxyfunctional siloxane Acetylation $+6 \%$ acetoxyfunctional siloxane; $\rightarrow$ Acetylation $+10 \%$ acetoxyfunctional siloxane;

- Acetylation $+20 \%$ acetoxyfunctional siloxane

Fig. 8 Water uptake of acetylated wood in combination with different ratios of acetoxy-functional siloxane: a first submersion, b fourth submersion, c WRE in first submersion, d WRE in fourth submersion

from the high amount of siloxane in the treatment solution (see above for the decrease in acetyl content).

Micro-pore blocking was previously discussed as the main reason for fungal resistance imparted by chemical modifications such as acetylation (Hill et al. 2005). Blocking of cell wall pores can reduce the availability of water as well as the penetration of enzymes (Papadopoulos and Hill 2002). A threshold value of approximately $20 \%$ WPG was found to impart fungal resistance by acetylation,

Table 1 WPG and mass loss in a fungal decay test after 16-week incubation with $C$. puteana (pine) and T. versicolor (beech) (mean values and, in brackets, standard deviations)

\begin{tabular}{lcclcc}
\hline & \multicolumn{2}{c}{ Pine sapwood } & & \multicolumn{2}{l}{ Beech wood } \\
& WPG (\%) & Mass loss (\%) & & WPG (\%) & Mass loss (\%) \\
\hline Control & - & $28.0(9.8)$ & & - & $25.2(1.9)$ \\
Acetylation 1 h & $0.5(0.1)$ & $33.0(3.1)$ & & $2.5(0.4)$ & $20.1(1.6)$ \\
Acetylation + siloxane 1 h & $8.6(0.8)$ & $35.5(4.1)$ & & $5.5(1.2)$ & $21.5(2.0)$ \\
Acetylation 2 h & $4.5(0.3)$ & $26.0(4.9)$ & & $10.2(0.2)$ & $\mathbf{1 1 . 5 ( 0 . 9 )}$ \\
Acetylation + siloxane 2 h & $12.5(0.4)$ & $29.7(10.4)$ & & $15.6(0.9)$ & $\mathbf{1 4 . 2 ( 1 . 5 )}$ \\
\hline
\end{tabular}

Bold values are significantly different from each other with $95 \%$ confidence 
which is accompanied with cell wall bulking of approximately $8 \%$ in case of Scots pine sapwood (experimental results by the authors). A reduction in fungal decay has been reported previously for various functionalized siloxanes. Ghosh et al. (2012) attributed the effectiveness of siloxane treatment against fungal decay to the penetration of the siloxanes into the cell wall and micro-pore blocking as well as interaction with the cell wall. Treatment with amino siloxanes-induced fungal resistance to wood when a bulking value of approximately $4 \%$ was reached (Ghosh 2009). Cell wall bulking of $4 \%$, however, cannot impart complete fungal resistance if the modification chemical is biologically inactive. It is therefore assumed that amino silicones used by Ghosh et al. (2012) exhibited a certain biological effectiveness in addition to micro-pore blocking. This effectiveness probably depends on the mobility of the siloxane chain, because higher effectiveness of the materials was found, when chain length decreased (Ghosh et al. 2012). In contrast to amino siloxanes used by Ghosh et al. (2012), acetoxy-functionalized siloxanes were applied in this study, which are able to undergo condensation and form a threedimensional network within the wood. In this network, the siloxane chains are immobilised which is also evident in a completely stable WPG after severe leaching (data not shown). This immobility and the lack of functionality are the reasons why the siloxanes do not affect the physiology of decay fungi and do not prevent fungal decay. Many studies have previously shown the biological inertness of siloxanes with longer chain length (Ackermann and Damrath 1989; Noll 1968).

\section{Mechanical properties}

Specimens treated with mixtures of AA and acetoxy-functional siloxane displayed a slightly greater maximum swelling in water than solely acetylated specimens. A similar result was found by Obataya et al. (2002), combining acetylation with a bulking treatment of glucose-pentaacetate. Greater swelling can be attributed to "solving" or weakening of lignin or to a distortion of the crystalline parts of cellulose. To investigate, if this has any effect on the mechanical properties, a bending test and an impact bending test were performed (Table 2).

Analysis of variance revealed that the bending strength and the modulus of elasticity did not exhibit any significant differences at a $5 \%$ confidence level. The impact bending strength of acetylated wood was significantly higher than that of the

Table 2 Results of mechanical tests (mean values and, in brackets, standard deviations)

\begin{tabular}{lllllc}
\hline & $\begin{array}{l}\text { Bending } \\
\text { strength } \\
\left(\mathrm{N} \mathrm{mm}^{-2}\right)\end{array}$ & $\begin{array}{l}\text { Modulus of } \\
\text { elasticity } \\
\left(\mathrm{N} \mathrm{mm}^{-2}\right)\end{array}$ & $\begin{array}{l}\text { Impact bending } \\
\text { strength } \\
\left(\mathrm{kJ} \mathrm{m}^{-2}\right)\end{array}$ & WPG (\%) & $\begin{array}{l}\text { Equilibrium moisture } \\
\text { content at 20 } \\
\mathrm{RH}(\%)\end{array}$ \\
\hline Control & $119(11)$ & $13,200(1,276)$ & $30,285(7,855)$ & - & $10.6(0.1)$ \\
Acetylation & $138(22)$ & $13,183(1,510)$ & $43,513(9,992)$ & $21.0(0.3)$ & $5.2(0.1)$ \\
$+1 \%$ Siloxane & $138(25)$ & $13,000(1,669)$ & $36,310(9,733)$ & $21.6(0.3)$ & $5.2(0.1)$ \\
$+5 \%$ Siloxane & $122(26)$ & $12,256(1,516)$ & $40,047(7,381)$ & $24.1(0.2)$ & $5.2(0.1)$ \\
$+10 \%$ Siloxane & $141(17)$ & $13,583(1,164)$ & $34,758(11,945)$ & $28.7(0.4)$ & $5.2(0.0)$ \\
\hline
\end{tabular}


control specimens with $95 \%$ confidence. There were, however, no differences between the solely acetylated wood and acetylated wood combined with siloxane.

\section{Conclusion}

Combining acetylation with polysiloxane treatment can enhance the water repellence of acetylated wood without any apparent drawbacks. ASE, mechanical properties and fungal resistance were not changed by the treatment. Small amounts of siloxane are sufficient to reduce water uptake to a great extent, because only the inner surfaces of the wood need to be covered by the siloxane. Fungal resistance of acetylated wood is solely brought about by the acetyl content; fungal resistance is not increased by introduction of acetoxy-functional siloxane probably because of the immobility of the condensed siloxane in the wood.

Acknowledgments The authors would like to acknowledge the contribution of Momentive GmbH, Leverkusen, Germany, for supplying the polysiloxanes and technical information.

Open Access This article is distributed under the terms of the Creative Commons Attribution License which permits any use, distribution, and reproduction in any medium, provided the original author(s) and the source are credited.

\section{References}

Ackermann J, Damrath V (1989) Chemie und Technologie der Silicone II. Herstellung und Verwendung von Siliconpolymeren. Chem unserer Zeit 23:86-99

Bereck A, Riegel D, Matzat A, Habereder P, Lautenschlager H (2001) Silicones in fibrous substrates: their mode of action. AATCC Rev 1:45-49

Brelid PL, Simonson R, Bergman O, Nilsson T (2000) Resistance of acetylated wood to biological degradation. Holz Roh Werkst 58:331-337

Chang ST, Chang HT (2001) Comparisons of the photostability of esterified wood. Polym Degrad Stab 71:261-266

DIN 52186 (1978) Testing of wood; bending test. Deutsches Institut für Normung e.V, Berlin

DIN 52189 (1981) Testing of wood; determination of impact bending strength. Deutsches Institut für Normung e.V, Berlin

DIN EN 113 (1996) Prüfverfahren zur Bestimmung der vorbeugenden Wirksamkeit gegen holzzerstörende Basidiomyceten. Deutsches Institut für Normung e.V, Berlin

DIN EN 84 (1997) Beschleunigte Alterung von behandeltem Holz vor biologischen Prüfungen. Deutsches Institut für Normung e.V, Berlin

Donath S, Militz H, Mai C (2006) Creating water-repellent effects on wood by treatment with silanes. Holzforschung 60:40-46

Eastman S, Lesser A, McCarthy $\mathrm{T}$ (2009) Supercritical $\mathrm{CO}_{2}$-assisted, silicone-modified wood for enhanced fire resistance. J Mater Sci 44:1275-1282

Ghosh SC (2009) Wood modification with functionalized polydimethylsiloxanes. Dissertation, Georg August University of Göttingen

Ghosh SC, Dyckmans J, Militz H, Mai C (2012) Effect of quat- and aminosilicones on fungal colonisation and decay of wood. Holzforschung 66(8):1009-1015

Hager R (1995) Waterborne silicones as wood preservatives. International Research Group on Wood Protection, IRG/WP 95-30062 Stockholm, Sweden

Hill CAS, Forster SC, Farahani MRM, Hale MDC, Ormondroyd GA, Williams GR (2005) An investigation of cell wall micropore blocking as a possible mechanism for the decay resistance of anhydride modified wood. Int Biodeterior Biodegradation 55:69-76 
Kim BT (2001) Grundlegende Untersuchungen zur Hydrophobierung von Textilien mit Polyorganosiloxanen. Dissertation, Faculty University of Wuppertal

Lukowsky D, Peek RD, Rapp AO (1997) Water-based silicones in wood. International Research Group on Wood Protection, IRG/Wp 97-30144 Stockholm, Sweden

Mantanis GI, Young RA, Rowell RM (1994) Swelling of wood.2. Swelling in organic liquids. Holzforschung 48:480-490

Mayer H (1998) Masonry protection with silanes, siloxanes and silicone resins. JOCCA—Surf Coat Int 81:89-93

Naik S, Bhattacharjya G, Talukdar B, Patel Bhisma K (2004) Chemoselective acylation of amines in aqueous media. Eur J Org Chem 2004:1254-1260

Noll W (1968) Chemie und Technologie der Silikone, 2nd edn. Verlag Chemie, Weinheim

Obataya E, Minato K (2008) Potassium acetate-catalyzed acetylation of wood: extraordinarily rapid acetylation at $120^{\circ} \mathrm{C}$. Wood Sci Technol 42:567-577

Obataya E, Masaki S, Bunichiro T (2002) Dimensional stability of wood acetylated with acetic anhydride solution of glucose pentaacetate. J Wood Sci 48:315-319

Papadopoulos AN, Hill CAS (2002) The biological effectiveness of wood modified with linear chain carboxylic acid anhydrides against Coniophora puteana. Holz Roh Werkst 60:329-332

prCEN/TS 15083-1 (2004) Durability of wood and wood based products-determination of the natural durability of solid wood against wood-destroying fungi-test methods part 1: basiodiomycetes. European committee for standardization, Brussels

Rowell RM (1983) Chemical modification of wood. Forest Prod Abstr 6:363-382

Stamm AJ (1964) Wood and cellulose science. The Ronald Press Company, New York

Weigenand O, Militz H, Tingaut P, Sebe G, de Jeso B, Mai C (2007) Penetration of amino-silicone microand macro-emulsions into Scots pine sapwood and the effect on water-related properties. Holzforschung 61:51-59

Xiao Z, Xie Y, Militz H, Mai C (2010) Effect of glutaraldehyde on water related properties of solid wood. Holzforschung 64:483-488 